\title{
Validation of the Maslach Burnout Inventory-Human Services Survey for Estimating Burnout in Dental Students
}

\author{
José María Montiel-Company, DDS, MD, PhD; Cristian Subirats-Roig, DDS; Pau Flores- \\ Martí, DDS; Carlos Bellot-Arcís, DDS, PhD; José Manuel Almerich-Silla, MD, DMD, PhD
}

Abstract: The aim of this study was to examine the validity and reliability of the Maslach Burnout Inventory-Human Services Survey (MBI-HSS) as a tool for assessing the prevalence and level of burnout in dental students in Spanish universities. The survey was adapted from English to Spanish. A sample of 533 dental students from 15 Spanish universities and a control group of 188 medical students self-administered the survey online, using the Google Drive service. The test-retest reliability or reproducibility showed an Intraclass Correlation Coefficient of 0.95 . The internal consistency of the survey was 0.922 . Testing the construct validity showed two components with an eigenvalue greater than 1.5 , which explained $51.2 \%$ of the total variance. Factor I (36.6\% of the variance) comprised the items that estimated emotional exhaustion and depersonalization. Factor II (14.6\% of the variance) contained the items that estimated personal accomplishment. The cut-off point for the existence of burnout achieved a sensitivity of $92.2 \%$, a specificity of $92.1 \%$, and an area under the curve of 0.96 . Comparison of the total dental students sample and the control group of medical students showed significantly higher burnout levels for the dental students ( $50.3 \%$ vs. $40.4 \%)$. In this study, the MBI-HSS was found to be viable, valid, and reliable for measuring burnout in dental students. Since the study also found that the dental students suffered from high levels of this syndrome, these results suggest the need for preventive burnout control programs.

José María Montiel-Company is Teaching Assistant, Department of Stomatology, Faculty of Medicine and Dentistry, University of Valencia, Spain; Cristian Subirats-Roig is Postgraduate Student, Department of Stomatology, Faculty of Medicine and Dentistry, University of Valencia, Spain; Pau Flores-Martí is Postgraduate Student, Department of Stomatology, Faculty of Medicine and Dentistry, University of Valencia, Spain; Carlos Bellot-Arcís is Associate Lecturer, Department of Stomatology, Faculty of Medicine and Dentistry, University of Valencia, Spain; and José Manuel Almerich-Silla is Tenured Lecturer, Department of Stomatology, Faculty of Medicine and Dentistry, University of Valencia, Spain. Direct correspondence to Dr. José Manuel Almerich-Silla, Department d'Estomatologia, Universitat de València, C/ Gascó Oliag 1, 46010-Valencia, Spain; +34963864144; jose.m.almerich@uv.es.

Keywords: dental education, dental students, stress, burnout

Submitted for publication 1/15/16; accepted 4/30/16

$\mathrm{F}$ reudenberger defined burnout as "feelings of failure and being worn or wrung out, resulting from an overload of claims on energy, on personal resources, or on the spiritual strength of the worker." In 1986, Maslach and Jackson defined it as "a syndrome of emotional exhaustion, depersonalization, and reduced personal accomplishment that can occur among individuals who do 'people work' of some kind."2 Owing to the presence of a series of stress factors, individuals experience prolonged exposure to stress, which results in chronic fatigue and inefficacy at work, among other possible symptoms.

At present, the Maslach Burnout Inventory (MBI) is the survey most frequently used for evaluating burnout syndrome. ${ }^{3}$ It has proved valid and reliable and enjoys wide acceptance around the world. There are several versions, mainly the MBI-Human Services Survey (MBI-HSS), to assess burnout among health care professionals, in addition to the MBI-Educators Survey and the MBI-General Survey. ${ }^{3-5}$ The fact that the first survey to measure burnout was designed exclusively for health professionals is an indication of the high risk of the syndrome in this sector. In health care occupations, the professional-patient relationship plays an important part in burnout syndrome. As a result of this relationship, a wide range of factors appear that increase health professionals' risk of burnout. The rise in research on burnout syndrome has led to the concept's being extended to all types of occupations and even to university students (academic burnout), as work is understood in a wider sense and students are considered workers who can become worn out and suffer burnout. The publication of the Maslach Burnout Inventory-Student Survey (MBI-SS) has made it possible to measure burnout outside the occupational sphere by defining its dimensions with reference to studying. In this way, it has proved 
possible to demonstrate that students also experience burnout caused by their studies. ${ }^{6}$

Dental students can be exposed to high levels of burnout as they combine the burnout risk factors of health care workers and university students. Using the MBI-HSS to measure these students' burnout was preferable in our study as it includes questions about clinical practice, which the MBI-SS does not. Several studies have found high burnout levels in dental students. ${ }^{7-11}$ Alzahem et al. suggested using tools to determine the signs and symptoms of stress among dental students. ${ }^{9}$ Atalayin et al. suggested raising the students' awareness from the preclinical years in order to avoid burnout. ${ }^{10}$ Gorter et al. recommended that dental schools should consider it important to prevent psychological stress among their students. ${ }^{11}$

In Spain, the dental degree requires 60 credits a year for five years, totalling 300 European Credit Transfer System (ECTS) credits. An ECTS credit is equivalent to 25 hours' work by the student: ten to 15 hours of learning depending on the subject and the remaining time engaged in individual study. Clinical practice with real patients is progressively introduced from the third year onwards. The distribution of hours in the last three years, divided into clinical practice, theory, laboratory, and other (seminars, computers, research, etc.), is shown in Figure 1. In view of the lack of a validated instrument for measuring the degree of burnout among dental students and of the high levels of burnout found in previous studies, the aims of our study were to assess the validity and reliability of the MBI-HSS as an instrument for determining the level of burnout among dental students in relation to their clinical practice with patients and to determine its incidence in a sample of dental students at Spanish universities.

\section{Materials and Methods}

The study was approved by the University of Valencia Ethics Committee (registration number H1393443008531). The instrument used to collect the data was the MBI-HSS for human services professionals. ${ }^{2}$ The survey consists of 22 items grouped into three dimensions. The emotional exhaustion dimension (which refers to a chronic state of physical and emotional depletion that results from excessive and continuous stress) consists of nine items (numbers $1,2,3,6,8,13,14,16$, and 20). The depersonalization dimension (which refers to a set of callous and insensitive behaviors demonstrated by a worker toward a patient) consists of five items (numbers 5 , $10,11,15$, and 22). The personal accomplishment dimension (which refers to negative self-evaluation) consists of eight items (numbers 4, 7, 9, 12, 17, 18, 19 , and 21).

The students scored each item on the survey on a rating scale to show the frequency with which they had experienced the situation described over the past year. Response options on the seven-point scale were $0=$-never, $1=$ some times a year or less often, $2=$ once a month or less often, $3=$ several times a month, $4=$ once a week, $5=$ several times a week, and 6=daily. In the dimensions of emotional exhaustion and depersonalization, high scores correspond to high feelings of burnout, while in the personal accomplishment at work dimension it is the low scores that correspond to high burnout feelings.

The questionnaire was adapted transculturally from English to Spanish. Two independent translators each translated it independently and then reached a consensus on a first version in Spanish. A third translator back-translated it into English and reported on the semantic differences. A pilot test was conducted with 33 undergraduate dental students at the University of Valencia, Spain, to check for difficulties in interpretation, confirm the viability of the questionnaire, and establish the definitive MBI-HSS version for these dental students (the survey is available from the corresponding author). No changes were introduced during this qualitative stage.

The survey was administered online through the Google Drive service. Students in the third, fourth, and fifth years of the dental curriculum in Spain were contacted by email at the addresses provided by the National Association of Dentistry Students (ANEO). The sample size was calculated by estimating a potential population of 5,000 dental students in Spain, a 95\% confidence level, 4\% precision, and $50 \%$ prevalence of burnout as the worst-case scenario. The required sample size was 536 students. The online questionnaire remained available for completion from November 18,2013 , to May 8, 2014. The dissemination medium employed was social networks, which are very popular among the university population. The call to complete the survey was repeated at two-month intervals in order to recruit as many respondents as possible. In addition to the dental students recruited as a test group, 188 second-cycle medical students at the University of Valencia were included as a control group. These were fourth-, fifth-, and sixth-year medical students who had clinical practice with patients in hospitals. 


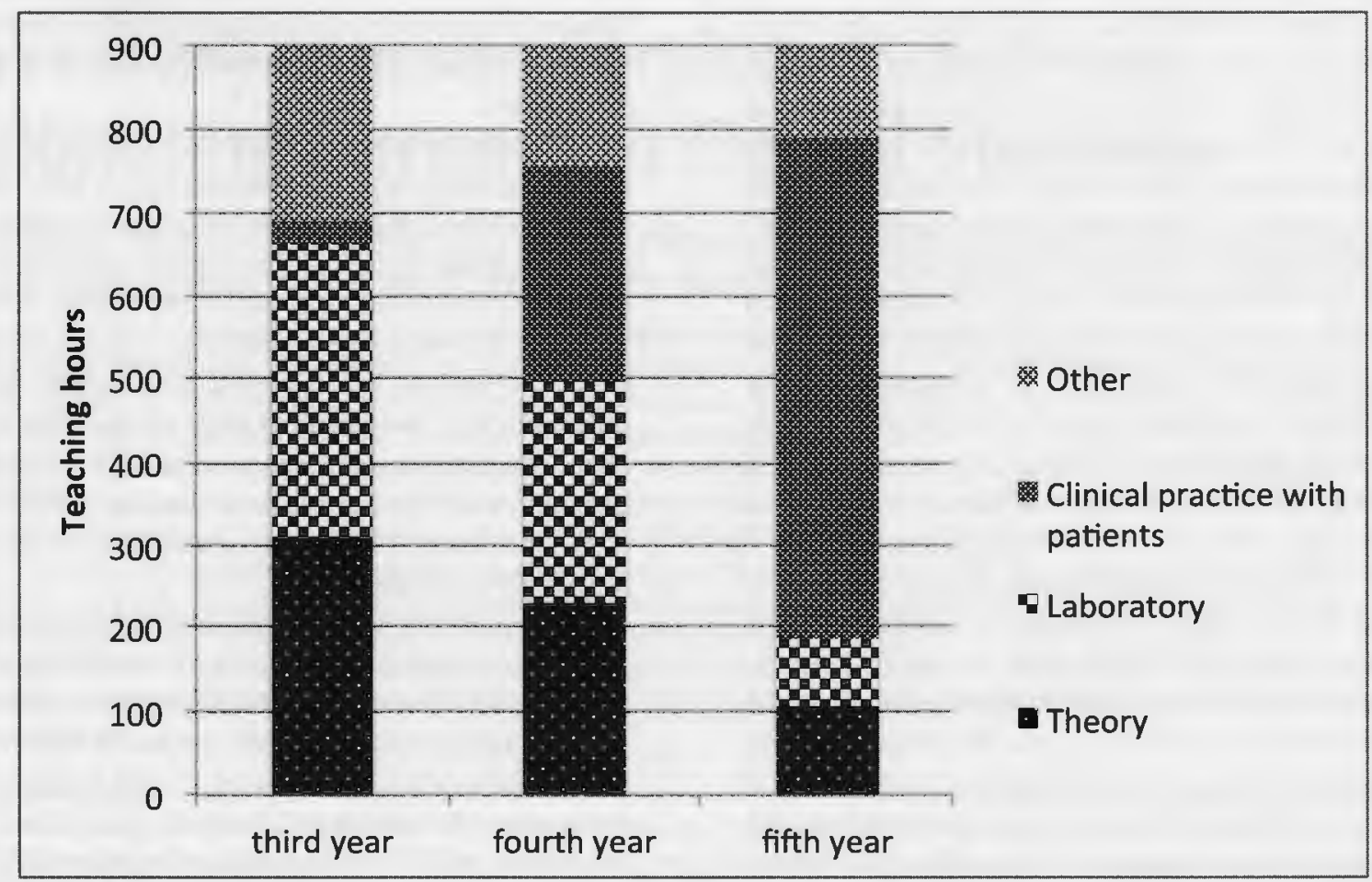

Figure 1. Distribution of teaching hours per year in third, fourth, and fifth years in dental education in Spain

The reproducibility of the survey was assessed with 33 students who self-administered it in a pilot test. These students were assigned an identification code that made it possible to re-administer the same questionnaire to them two weeks later to assess its reproducibility by means of the Intraclass Correlation Coefficient (ICC). The internal consistency of the survey was tested by Cronbach's alpha. The validity of the construct was tested by factor analysis of the principal components with varimax rotation. This test was conducted to discover the internal structure of the survey in order to detect items that were correlated because they belonged to the same dimension. An item was considered to belong to a dimension when its correlation value was at least 0.4 . The criterion validity was assessed by studying the sensitivity, specificity, and receiver operating characteristic (ROC) curves of item 23: "How burned out do you feel from your course?" This item was not part of the adapted MBI-HSS. It was added to the pilot test survey to act as the gold standard for burnout and was scored on a five-point scale with $0=$ not at all, $1=$ very little, $2=\mathrm{a}$ little, $3=$ some, and $4=$ =very. The area under the curve (AUC) of the ROC curve, with values ranging from 0 to 1 , measured the diagnostic effectiveness of the survey in detecting individuals who were really affected by burnout. Values over 0.8 were considered to indicate very good diagnostic effectiveness. The scores for each dimension of the MBI survey and the total MBI score were calculated with their means and confidence intervals (95\% CI). To calculate the total MBI score, the scores for the individual dimensions were added together, reversing the direction of the accomplishment dimension score so that it measured burnout.

The data analysis was performed with SPSS v. 22.0 software. Surveys on which fewer than $80 \%$ of the items had been completed were excluded. In the surveys that were not excluded, items that had not been answered were assigned the mean score of the study population for that item. ANOVA comparison of means and the Bonferroni post-hoc test were used to compare the results from different years of the dental course and ascertain whether there were any significant differences between them. Student's t-test was used to investigate whether there were statistically significant differences between the two genders and between the dental students and the 
medical student control group. The significance level was set at $\mathrm{p}<0.05$.

\section{Results}

Of the 559 surveys received from dental students, 26 were eliminated because they did not meet the completion criterion. The final sample for the test group thus consisted of 533 dental students at 15 Spanish universities who met all the defined criteria. By gender, $34.7 \%$ of the 533 dental students were men, and $65.3 \%$ were women. Of the 188 medical students who served as a control group, $33.3 \%$ were men, and $66.7 \%$ were women. The mean age of the dental students was 21.9 years (range: $19-30$ years). The mean age of the medical students was 22.8 years (range: 19-33 years). Surveys were received from 15 Spanish universities, with a mean of 38 respondents per university (range: 15-55 respondents).

The test-retest reliability or reproducibility showed an ICC of 0.95 for the survey as a whole. The Cronbach's alpha statistic for its internal consis-

Table 1. Internal consistency of Maslach Burnout Inventory adapted for Spanish dental students

\begin{tabular}{cccc} 
Item & $\begin{array}{c}\text { Original } \\
\text { Dimension }\end{array}$ & $\begin{array}{c}\text { Corrected } \\
\text { Element- } \\
\text { Total } \\
\text { Correlation }\end{array}$ & $\begin{array}{c}\text { Cronbach's } \\
\text { Alpha If } \\
\text { Element } \\
\text { Eliminated }\end{array}$ \\
\hline 1 & Exhaustion & 0.419 & 0.921 \\
2 & Exhaustion & 0.260 & 0.922 \\
3 & Exhaustion & 0.358 & 0.922 \\
4 & Accomplishment & 0.516 & 0.920 \\
5 & Depersonalization & 0.594 & 0.918 \\
6 & Exhaustion & 0.557 & 0.919 \\
7 & Accomplishment & 0.604 & 0.918 \\
8 & Exhaustion & 0.607 & 0.918 \\
9 & Accomplishment & 0.627 & 0.917 \\
10 & Depersonalization & 0.641 & 0.917 \\
11 & Depersonalization & 0.606 & 0.918 \\
12 & Accomplishment & 0.661 & 0.917 \\
13 & Exhaustion & 0.655 & 0.917 \\
14 & Exhaustion & 0.507 & 0.920 \\
15 & Depersonalization & 0.536 & 0.919 \\
16 & Exhaustion & 0.646 & 0.917 \\
17 & Accomplishment & 0.609 & 0.918 \\
18 & Accomplishment & 0.701 & 0.916 \\
19 & Accomplishment & 0.587 & 0.918 \\
20 & Exhaustion & 0.632 & 0.917 \\
21 & Accomplishment & 0.591 & 0.918 \\
22 & Depersonalization & 0.506 & 0.920 \\
& Cron & &
\end{tabular}

Note: Cronbach's alpha statistic for internal consistency of survey was 0.922 . tency was 0.922 (Table 1). The Barlett's sphericity test result was significant $(p<0.001)$, and the KaiserMeyer-Olkin measure of sampling adequacy exceeded 0.91 . Testing the construct validity by applying the principal components method with varimax rotation (Table 2) revealed two components with an eigenvalue greater than 1.5 that explained $51.2 \%$ of the total variance. Factor I, which explained $36.6 \%$ of the variance, comprised the items that estimated emotional exhaustion and depersonalization $(1,2,3$, $5,6,8,10,11,13,14,15,16,20$, and 22). Factor II, which explained $14.6 \%$ of the variance, comprised items $4,7,9,12,17,18,19$, and 21 ; those estimated personal accomplishment.

The criterion validity was measured by the number of respondents who answered 3 (quite) or 4 (very) to question 23, "How burned out do you feel from your course?" (added at the end of the 22-item survey for the pilot test), which constituted the gold standard for burnout. This resulted in an AUC of 0.90 ( $95 \% \mathrm{CI} 0.88-0.93$ ) for the dimensions of emotional exhaustion/depersonalization and 0.85 (95\% Cl 0.810.88 ) for the personal accomplishment dimension.

Table 2. Principal components analysis of Maslach Burnout Inventory adapted for Spanish dental students

\begin{tabular}{|c|c|c|c|}
\hline Item & $\begin{array}{l}\text { Original } \\
\text { Dimension }\end{array}$ & $\begin{array}{c}\text { Component } 1 \\
36.6 \% \text { of } \\
\text { Variance } \\
\text { Emotional } \\
\text { Exhaustion/ } \\
\text { Depersonalization }\end{array}$ & $\begin{array}{c}\text { Component } 2 \\
14.6 \% \text { of } \\
\text { Variance } \\
\text { Personal } \\
\text { Accomplish- } \\
\text { ment }\end{array}$ \\
\hline 1 & Exhaustion & 0.619 & 0.043 \\
\hline 2 & Exhaustion & 0.400 & 0.015 \\
\hline 3 & Exhaustion & 0.630 & -0.088 \\
\hline 4 & Accomplishment & 0.058 & 0.701 \\
\hline 5 & Depersonalization & 0.558 & 0.318 \\
\hline 6 & Exhaustion & 0.708 & 0.158 \\
\hline 7 & Accomplishment & 0.070 & 0.798 \\
\hline 8 & Exhaustion & 0.763 & 0.130 \\
\hline 9 & Accomplishment & 0.084 & 0.834 \\
\hline 10 & Depersonalization & 0.715 & 0.198 \\
\hline 11 & Depersonalization & 0.715 & 0.171 \\
\hline 12 & Accomplishment & 0.327 & 0.663 \\
\hline 13 & Exhaustion & 0.668 & 0.329 \\
\hline 14 & Exhaustion & 0.629 & 0.107 \\
\hline 15 & Depersonalization & 0.442 & 0.363 \\
\hline 16 & Exhaustion & 0.711 & 0.202 \\
\hline 17 & Accomplishment & 0.163 & 0.776 \\
\hline 18 & Accomplishment & 0.265 & 0.832 \\
\hline 19 & Accomplishment & 0.163 & 0.784 \\
\hline 20 & Exhaustion & 0.721 & 0.178 \\
\hline 21 & Accomplishment & 0.121 & 0.743 \\
\hline 22 & Depersonalization & 0.532 & 0.197 \\
\hline
\end{tabular}


For the total MBI score (Figure 2), the AUC was 0.96 (95\% CI 0.95-0.98).

When we compared the results by dental student year, significant differences were found. The fourth-year students had significantly higher scores for exhaustion/depersonalization and total MBI and significantly lower scores for personal accomplishment than the other years (Table 3). Additionally, the dental students as a whole showed a higher prevalence of burnout than the control group (Table 4). Significant differences by gender were not found between the two factor components, among any of the years, or between the total dental students and the control group ( $\mathrm{p}>0.05)$.

Taking the cut-off point for burnout as $\mathbf{5 7 . 5}$ or higher on the total MBI score, the survey sensitivity was $92.2 \%$, its specificity $92.1 \%$, and its diagnostic efficacy (AUC) 0.96 , and significant differences were found among the three dental student year groups, as burnout was $73.7 \%$ in the fourth year, $58.4 \%$ in the third year, and $28.2 \%$ in the fifth year. Comparison of the total dental students and the control group of medical students showed significantly higher burnout levels for the dental students ( $50.3 \%$ vs. $40.4 \%)$.

\section{Discussion}

The MBI-HSS enjoys wide support as a tool for assessing burnout among health care personnel and specifically among professionals working in the field of dentistry. ${ }^{2,12}$ There is also a version to assess burnout among students in general: the MBI-SS. ${ }^{6}$ However, we decided that the student version was not appropriate for this study because dental students begin their clinical practice in the third year and their burnout cannot be measured without a tool that takes interaction with patients into account. ${ }^{8}$ The implications of the presence of burnout among dental students in the exercise of their profession could

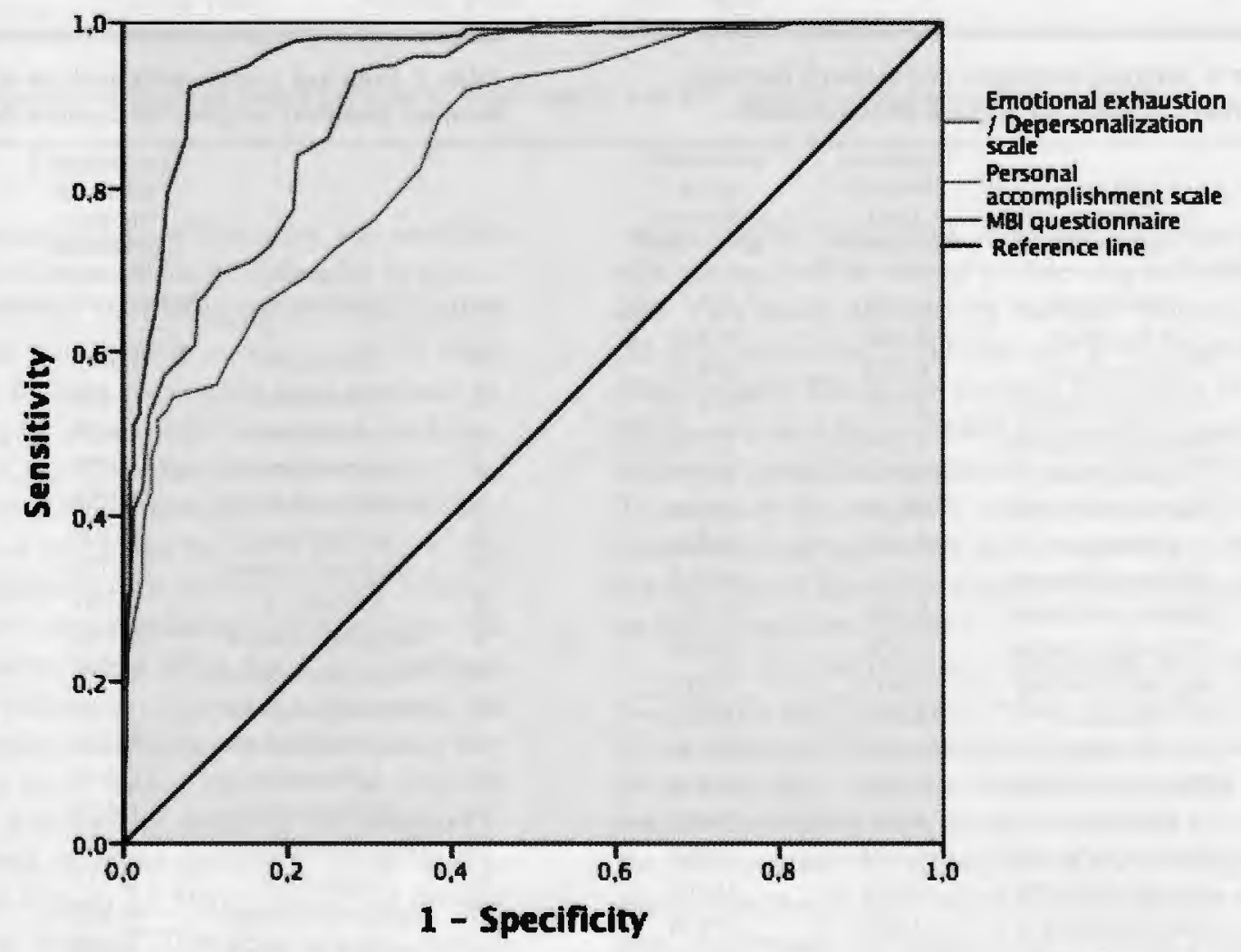

Figure 2. Receiver operating characteristic (ROC) of Maslach Burnout Inventory for Spanish dental students

Note: Optimum cut-off point of the survey to determine burnout was 57.5. With this cut-off point, the sensitivity of the survey was $92.2 \%$ and the specificity was $92.1 \%$. The diagnostic efficacy (AUC) was 0.96 . 
Table 3. Mean score for each dimension and for total Maslach Burnout Inventory, by group

\begin{tabular}{|c|c|c|c|c|c|}
\hline Dimension & Group & Mean Score & $\begin{array}{c}95 \% \\
\text { Confidence } \\
\text { Interval } \\
\end{array}$ & p-value & $\begin{array}{c}\text { Bonferroni } \\
\text { post-hoc } \\
p<0.05 \\
\end{array}$ \\
\hline \multirow{5}{*}{$\begin{array}{l}\text { Emotional exhaustion/ } \\
\text { depersonalization }\end{array}$} & Dental 3rd year $(n=161)$ & 37.9 & $36.2-39.6$ & \multirow{3}{*}{$\begin{array}{l}\text { ANOVA test } \\
p=0.0001^{*}\end{array}$} & \multirow{5}{*}{$\begin{array}{l}4 \text { th vs } 3 \text { rd } \\
4 \text { th vs } 5 \text { th } \\
3 \text { rd vs } 5 \text { th }\end{array}$} \\
\hline & Dental 4th year $(n=152)$ & 48.4 & $46.3-50.5$ & & \\
\hline & Dental 5th year $(n=220)$ & 32.8 & $30.9-34.6$ & & \\
\hline & Dental total $(n=533)$ & 38.8 & $37.5-40.0$ & \multirow{2}{*}{$\begin{array}{l}\text { Student's t-test } \\
\qquad \mathrm{p}=0.035^{*}\end{array}$} & \\
\hline & Medical $(n=188)$ & 36.2 & $33.9-38.4$ & & \\
\hline \multirow[t]{5}{*}{ Personal accomplishment } & Dental 3rd year $(n=161)$ & 29.6 & 28.3-30.9 & \multirow{3}{*}{$\begin{array}{l}\text { ANOVA test } \\
p<0.0001^{*}\end{array}$} & \multirow{5}{*}{$\begin{array}{l}\text { 4th vs 3rd } \\
4 \text { th vs } 5 \text { th } \\
3 \text { rd vs } 5 \text { th }\end{array}$} \\
\hline & Dental 4th year $(n=152)$ & 26.1 & $24.2-27.9$ & & \\
\hline & Dental 5th year $(n=220)$ & 34.3 & $33.3-35.4$ & & \\
\hline & Dental total $(n=533)$ & 30.5 & 29.7-31.4 & \multirow{2}{*}{$\begin{array}{l}\text { Student's t-test } \\
\mathbf{p}<0.0001^{*}\end{array}$} & \\
\hline & Medical $(n=188)$ & 35.5 & $34.6-36.4$ & & \\
\hline \multirow[t]{5}{*}{ Maslach Burnout Inventory } & Dental 3rd year $(n=161)$ & 56.3 & $54.1-58.6$ & \multirow{3}{*}{$\begin{array}{l}\text { ANOVA test } \\
p<0.0001^{*}\end{array}$} & \multirow{3}{*}{$\begin{array}{l}4 \text { th vs } 3 \text { rd } \\
4 \text { th vs } 5 \text { th } \\
3 \text { rd vs } 5 \text { th }\end{array}$} \\
\hline & Dental 4th year $(n=152)$ & 70.4 & $66.7-74.0$ & & \\
\hline & Dental 5th year $(n=220)$ & 46.4 & 43.9-48.9 & & \\
\hline & Dental total $(n=533)$ & 56.3 & $54.5-58.1$ & \multirow{2}{*}{\multicolumn{2}{|c|}{$\begin{array}{l}\text { Student's t-test } \\
\mathbf{p}<0.0001^{*}\end{array}$}} \\
\hline & Medical $(n=188)$ & 48.7 & $46.2-41.2$ & & \\
\hline *Significant at $p<0.05$ & & & & & \\
\hline
\end{tabular}

only be explained by their interaction with patients. Measuring the degree of burnout in the years that include clinical practice could assist in identifying the students most likely to suffer burnout in their future professional life.

Following transcultural adaptation, the pilot test, and psychometric tests, this study found that the survey was reliable and valid for assessing burnout among dental students in Spain. As regards the construct validity, the survey presented a two-factor structure. Although this result did not match the threefactor model proposed by Maslach and Jackson, ${ }^{2}$ previous studies have found that the factor solution can vary from that established by the authors of the MBI-HSS. For example, studies of psychometric factors have reproduced a three-component structure in their versions of the MBI-HSS, and others recommended solutions with a greater number of factors. ${ }^{13-16}$ The results of our study were consistent with those researchers who have recommended a two-factor solution. ${ }^{17-20}$ The first component covers the emotional exhaustion and depersonalization items, constituting what has been considered the core of the job burnout syndrome. ${ }^{21}$ In our study, the total variance explained by the two factors $(51.2 \%)$ was similar to the percentage found in two other studies, which reported $40.1 \%$ and $59 \% .^{13,14}$
Table 4. Prevalence of burnout in dental students by year and medical students (control group), measured with the Maslach Burnout Inventory

\begin{tabular}{lcc} 
Group & $\begin{array}{c}\text { Burnout } \\
\text { Percentage } \\
(\mathrm{Cl} 95 \%)\end{array}$ & p-value \\
\hline Dental 3rd year $(n=161)$ & $58.4 \%$ & $\mathrm{p}<0.001^{*}$ \\
& $(50.6-65.7)$ & \\
Dental 4th year $(n=152)$ & $73.7 \%$ & \\
& $(66.1-80.0)$ & \\
Dental 5th year $(n=220)$ & $28.2 \%$ & \\
& $(22.6-34.5)$ & \\
Dental total $(n=533)$ & $50.3 \%$ & $p<0.022 *$ \\
Medical students $(n=188)$ & $(46.0-54.1)$ & \\
& $40.4 \%$ &
\end{tabular}

*Significant at $p<0.05$, determined by chi-square tests

The criterion validity of the survey was tested by the pilot test addition of item 23 , used as the gold standard. This test showed that the diagnostic efficacy of the survey was high, with an AUC in excess of 0.95 and sensitivity and specificity values of over 0.9 for the cut-off point. These results show a high capacity for both detecting the students affected by burnout and excluding those not affected by this syndrome. 
A number of tools exist to measure burnout, but our comparison centered exclusively on those that employ the MBI. In our study, the fourth-year dental students showed a higher incidence of burnout than the third-and fifth-year students. This difference can be explained by the considerable increase in clinical experience in the fourth year. Since the clinical experience load is the same in the fourth and fifth years, the difference between them could be explained by the development of psychological defense mechanisms or by stress saturation in the final year of the degree. Amin et al. found that fourth-year students at Jordan University had higher levels of burnout than the fifth-year students, but Pöhlmann et al. found no differences between fourth- and fifth-year students in German universities. ${ }^{22,23}$

In a study conducted in seven European dental schools to assess the degree of psychological anguish, emotional exhaustion, and stress associated with the dental degree coursework, a very large proportion of the students experienced higher levels of emotional exhaustion than expected. ${ }^{7}$ In Spain, the results of our study were consistent with those of Galán et al., who found that fourth-year students had significantly higher burnout levels than second- and fifth-year students. ${ }^{8}$ Indeed, those researchers found that fourth-year dental students had double the burnout prevalence of fifth-year students. They also found a strong relationship between emotional exhaustion and depression. Among other factors, they noted that academic overload can contribute to differences in exhaustion, depression, and suicidal ideas among dental students.

Burnout is a multi-factor phenomenon that students may develop at an early stage. ${ }^{24}$ Mafla et al. associated the following factors with burnout: high social class, older students, married students, students with courses not yet completed, those who did not choose dentistry as their first option, and those studying at public universities or in overcrowded classes. ${ }^{25}$ Cecil et al. found that healthy behavior or lifestyles could prevent burnout in medical students in the United Kingdom. ${ }^{26}$ Actions to foster the students' well-being during the years of training have been recommended. . $7,28^{28}$

Our study found no significant differences in levels of burnout in relation to gender, but Campos et al. encountered a higher prevalence of the syndrome in men than in women..$^{29}$ They explained that a possible reason for this phenomenon is that women look to their families for support and help more often than men do. However, Amin et al. found significantly higher exhaustion among the women in their study. ${ }^{22}$

Prinz et al. compared the levels of burnout in dental students and medical students at the University of Erlangen-Nuremberg and found that more dental students than medical students suffered burnout syndrome. ${ }^{30}$ The fact that dental students work directly with patients, unlike medical students, may cause a considerable increase in the burden of responsibility they feel about applying their diagnostic and therapeutic skills, which would raise their burnout levels.

One of the main limitations of our study is that although using the social networks made it possible to obtain a broad sample and a rapid response, it is not impossible to rule out a possible response bias. Online distribution could have influenced the response, in that it is possible that only those who really experienced burnout responded, and the most-affected students would be more motivated to respond, leading to overestimation of the situation. An attempt was made to control other factors related to the academic year by keeping the survey open for six months and avoiding the final exam period, which obviously increases stress levels. The $76 \%$ response rate may be considered acceptable, and the fact that respondents were from 15 Spanish universities allows us to extrapolate the results to the entire student population of Spain.

As this was a cross-sectional study, cause-effect relations could not be established. However, comparison with the medical student control group warrants considering that the dental students presented high levels of burnout. It would therefore be appropriate to conduct future studies to clarify the source of this burnout and establish a series of preventive measures such as redesign of the traditional curriculum, individual professional guidance, and stress prevention and management education.

\section{Conclusion}

In this study, the MBI-HSS survey proved to be viable, valid, and reliable for measuring burnout among dental students. Dental students in the study demonstrated high levels of this syndrome.

\section{Acknowledgments}

The authors thank Mary Georgina Hardinge for translating the manuscript into English. 


\section{Disclosure}

The authors declared no financial, economic, or professional conflicts that may have influenced the design, execution, or presentation of this scholarly work.

\section{REFERENCES}

1. Freudenberger H. Staff burnout. J Soc Issues 1974;30: 159-65.

2. Maslach C, Jackson SE. The Maslach burnout inventory manual. Palo Alto, CA: Consulting Psychologists Press, 1986.

3. Maslach C, Jackson SE. The measurement of experienced burnout. J Occup Behav 1981;2:99-113.

4. Schwab RL. Burnout in education. In: Maslach C, Jackson $\mathrm{SE}$, eds. The Maslach burnout inventory: manual. Palo Alto, CA: Consulting Psychologists Press, 1986:18-22.

5. Schaufeli WB, Leiter MP, Maslach C, Jackson SE. Maslach burnout inventory general survey. In: Maslach C, Jackson SE, Leiter MP, eds. The Maslach burnout inventory: test manual. Palo Alto, CA: Consulting Psychologists Press, 1996.

6. Schaufeli WB, Salanova M, González-Romá V, Bakker A. The measurement of engagement and burnout: a two sample confirmatory factor analytic approach. J Happiness Stud 2002;3:71-92.

7. Humphris G, Blinkhorn A, Freeman R, et al. Psychological stress in undergraduate dental students: baseline results from seven European dental schools. Eur J Dent Educ 2002;6:22-9.

8. Galán F, Ríos-Santos JV, Polo J, et al. Burnout, depression, and suicidal ideation in dental students. Med Oral Patol Oral Cir Bucal 2014;19:e206-11.

9. Alzahem AM, van der Molen HT, Alaujan AH, et al. Stress amongst dental students: a systematic review. Eur J Dent Educ 2011;15:8-18.

10. Atalayin C, Balkis $M$, Tezel $H$, et al. The prevalence and consequences of burnout on a group of preclinical dental students. Eur J Dent 2015;9:356-63.

11. Gorter R, Freeman R, Hammen S, et al. Psychological stress and health in undergraduate dental students: fifthyear outcomes compared with first-year baseline results from five European dental schools. Eur J Dent Educ 2008;12:61-8.

12. Te Brake JH, Bouman AM, Gorter RC, et al. Using the Maslach burnout inventory among dentists: burnout measurement and trends. Community Dent Oral Epidemiol 2008;36:69-75.

13. Söderfeldt M, Söderfeldt B, Warg LE, Ohlson CG. The factor structure of the Maslach burnout inventory in two Swedish human service organizations. Scand J Psychol 1996;37:437-43
14. Gold Y, Bachelor P, Michael WB. The dimensionality of a modified form of the Maslach burnout inventory for university students in a teacher-training program. Educ Psychol Meas 1989;49:549-61.

15. Gil-Monte PR. Factorial validity of the Maslach burnout inventory (MBI-HSS) among Spanish professionals. Rev Saúde Publica 2005;39:1-8.

16. Densten I. Re-thinking burnout. J Organiz Behav 2001; 22:833-40.

17. Brookings JB, Boltob B, Brown CE, McEvoy A. Selfreported job burnout among female human service professionals. J Occup Behav 1985;6:143-50.

18. Chan DW, Hui EK. Burnout and coping among Chinese secondary school teachers in Hong Kong. Br J Educ Psychol 1995;65:15-25.

19. Dignam JT, Barrera M, West SG. Occupational stress, social support, and burnout among correctional officers. Am J Community Psychol 1986;14:177-93.

20. Kalliath TJ, O'Driscolll MP, Gillespie DF, Bluedorn AC. A test of the Maslach burnout inventory in three samples of health care professionals. Work Stress 2000;14:35-50.

21. Cox T, Tisserand M, Taris T. The conceptualization and measurement of burnout: questions and directions. Work Stress 2005;19:187-91.

22. Amin WM,Al-Ali MH, Duaibis RB, et al. Burnout among clinical dental students in the Jordanian universities. J Clin Med Res 2009;1:207-11.

23. Pöhlmann K, Jonas I, Ruf S, Harzer W. Stress, burnout, and health in the clinical period of dental education. Eur J Dent Educ 2005;9:78-84

24. Singh P, Aulak DS, Mangat SS, Aulak MS. Systematic review: factors contributing to burnout in dentistry. Occup Med (Lond), Oct. 5, 2015.

25. Mafla AC, Villa-Torres L, Polychronopoulou A, et al. Burnout prevalence and correlates amongst Colombian dental students: the STRESSCODE study. Eur J Dent Educ 2015; 19:242-50.

26. Cecil J, McHale C, Hart J, Laidlaw A. Behavior and burnout in medical students. Med Educ Online 2014;19:252-9.

27. Ishak W, Nikravesh R, Lederer S, et al. Burnout in medical students: a systematic review. Clin Teach 2013;10:242-5.

28. Wild K, Scholz M, Ropohl A, et al. Strategies against burnout and anxiety in medical education: implementation and evaluation of a new course on relaxation techniques (Relacs) for medical students. PLoS One 2014;9(12):e114967.

29. Campos JA, Jordani PC, Zucoloto ML, et al. Burnout syndrome among dental students. Rev Bras Epidemiol 2012;15:155-65.

30. Prinz P, Hertrich K, Hirschfelder U, de Zwaan M. Burnout, depression, and depersonalization: psychological factors and coping strategies in dental and medical students. GMS Z Med Ausbild 2012;29(1). 